\title{
Las funciones del Jefe del Gobierno en la Constitución de Marruecos de 2011 \\ The Duties of the Head of Government in the 2011 Moroccan Constitution
}

Abdessamad HALMI BERRABAH

Doctorando en la Universidad Autónoma de Barcelona

abdessamadhalmi@hotmail.com

Recibido 7/11/2016. Revisado y aprobado para publicación 21/2/2017

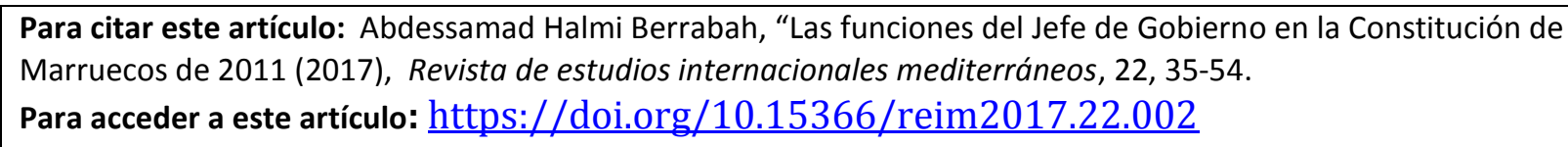

\section{Resumen}

El marco actual de la institución del jefe de Gobierno en Marruecos es reciente, aparece por primera vez con la Constitución de 2011, sus nuevas funciones fueron interpretadas por la nueva Ley Orgánica del Gobierno no 065-13. A pesar, del desarrollo político mencionado, el monarca, además de sus exclusivas competencias religiosas, continúa conservando importantes atribuciones que conviene poner en relación con las del jefe de Gobierno, lo que ha establecido por primera vez un sistema de poder ejecutivo compartido, y eso se irá aclarando a la hora de estudiar las funciones del jefe de Gobierno en relación con los demás Poderes del Estado.

Palabras clave: Marruecos, jefe de Gobierno, jefe del Estado, poder ejecutivo, poder legislativo

\section{Abstract}

The current framework of the institution of the Head of Government in Morocco is recent, first appeared with the Constitution of 2011, their new roles were interpreted by the new Organic Law No. 065-13 Government. Despite of the aforementioned political development, the monarch, in addition to his exclusive religious competences, continues to hold important powers that should be to put in relation to the Head of Government, which has first established a system of shared executive power, and that will become clearer at the time of studying the functions of the Chief Government in relation to the other Powers of State.

Key words: Morocco, Prime Minister, Head of State, Executive, Regulatory. 


\section{Introducción}

El objeto del presente trabajo es describir las facultades del jefe de Gobierno en Marruecos. El marco constitucional actual es reciente, pues la Constitución vigente data de 29 de julio de $2011^{1}$. Además, este texto aparece en un momento histórico particular que los medios de comunicación han denominado "la Primavera Árabe". Es más, puede que se trate de una reacción del poder para evitar males mayores en forma de revolución o cambios radicales de sistemas políticos, como aconteció en Túnez, Libia, y Egipto.

Los acontecimientos habrían empujado al Rey Mohamed VI, para evitar complicaciones futuras, a promover el inicio de unas reformas constitucionales profundas. Así, en su mensaje real dirigido a la nación el 9 de marzo de $2011^{2}$, el Monarca hace "una llamada a una reforma constitucional" 3 basada en los siguientes pilares: constitucionalizar el carácter multicultural de la nación, estabilizar el Estado de derecho, garantizar la independencia del Poder Judicial, forzar el principio de la separación de poderes para crear el equilibrio entre las instituciones constitucionales, ampliar el dominio de la ley, elegir al Gobierno saliente en unas elecciones generales, designar un "primer ministro", nombrado por el partido político mayoritario en las elecciones y reconocerle un verdadero poder ejecutivo.

La institución del jefe de Gobierno refleja perfectamente las tensiones generales del sistema de poderes en Marruecos, y una de las exigencias del movimiento reformador de 20 de febrero era precisamente reforzar ésta institución. También era una petición unánime de los partidos de la oposición en los años noventa del pasado siglo ${ }^{4}$. Con ello se pretendía potenciar el carácter parlamentario del sistema constitucional del Estado y ponerle freno a la influencia del "Majzén" 5 .

Para poder comprobar si efectivamente los poderes del jefe de Gobierno son los propios de un modelo de monarquía parlamentaria equiparable a la que se encuentra en numerosos países europeos, deben estudiarse con detenimiento las nuevas funciones del jefe del Gobierno y de su Gobierno. Por otro lado, las relaciones con los otros Poderes e instituciones serán también una información valiosa. Además, el estudio del ejercicio de las competencias del jefe de Gobierno

\footnotetext{
${ }^{1}$ Dahir (Edicto real) número 1-11-91 de 29 de Julio de 2011, B.O. número 5964 bis., de 30 de Julio de 2011, con la promulgación de la nueva Constitución del Reino de Marruecos, pág. 1902. Con la decisión del Consejo Constitucional (Tribunal Constitucional según la nueva Constitución) no 815.2011 de 14 de julio de 2011 proclamando los resultados del referéndum del 1 de julio de 2011.

${ }^{2}$ Discurso real del 9 de marzo de 2011, disponible en: http://www.chambredesrepresentants.ma/fr/discoursroyaux/discours-de-sm-le-roi-adresse-la-nation-le-09032011 [Consulta: 9 de junio de 2017].

3 Es importante señalar que la palabra "reforma" aparece en numerosas ocasiones -hasta nueve veces- en el mensaje real de 9 de marzo de 2011 e incluso "reforma profunda" aparece otras cinco veces.

${ }^{4}$ En referencia a los cuatro partidos que formaban la alianza opositora o "Kutla" (Partido de la Independencia, Unión Socialista de las Fuerzas Populares, P. Progreso y Socialismo, y la Organización por Trabajo Democrático Popular).

${ }^{5}$ El majzén es un concepto que suele aparecer en cierta bibliografía sobre Marruecos y de uso corriente en la cultura política marroquí. A fines del siglo XIX el majzén indica el Gobierno marroquí tal y como se constituye a partir de las distintas dinastías cherifianas (saâdíes y alauíes). Tras la independencia, en pleno siglo XX, el majzén pierde su uso oficial pero persiste en la vida sociopolítica. Actualmente se puede aprehender como estructura, como práctica de gobierno y como un conjunto de instituciones. Este «viejo nombre mágico» responde a la estructura del poder político marroquí conformado por dos círculos: uno, representa al sistema tradicional encarnado por el sultán, cherif, Emir Muminin; otro, al sistema moderno vertebrado en torno a un Rey jefe de Estado que reina y gobierna. Como forma de ejercer el poder, el majzén designa una manera de componer el aparato administrativo, de dirigir a los sujetos que lo nutren, se trata de una proyección de la familia y de la autoridad patriarcal sobre la organización estatal; es el rostro visible del neopatrimonialismo. El majzén alude también a una realidad institucional, en la que tienen cabida tanto las instituciones depositarias del poder formal, como el entramado paralelo de estructuras dotadas de poder material, ambas constituyen el armazón del sistema autoritario (Parejo, Mạ A. (2004) pp. 102-103).
} 
debería indicarnos cómo se interpretan los preceptos constitucionales, ya sea de manera favorable a los poderes ejecutivos del jefe de Gobierno o bien, por el contrario, reforzando los poderes residuales del monarca.

¿La Constitución habría establecido una monarquía parlamentaria? Es importante recordar el marco histórico: la institución real, durante las épocas de las cinco Constituciones anteriores, es decir 1962, 1970, 1972, 1992 y 1996, ha ejercido funciones de jefe del Poder ejecutivo, mientras el primer ministro no era más que un funcionario de la Casa Real ${ }^{6}$.

Del contenido de la Constitución de julio de 2011 se desprende, en cambio, que el jefe de Gobierno, por primera vez, dispone de auténticas atribuciones propias en la dirección del Poder Ejecutivo. El texto constitucional ha concretado las funciones principales que corresponden al Poder Ejecutivo ${ }^{7}$. Se dedica un título entero al jefe de Gobierno y su Gobierno, sin mención al rey. Veremos, con todo, que el Monarca conserva importantes atribuciones que conviene poner en relación con las del jefe de Gobierno.

Para explicar las funciones del jefe de Gobierno y las atribuciones del Monarca, existen dos modelos generales alternativos. Según una primera postura, la nueva Constitución, cuando menciona al Poder Ejecutivo, se refiere al Gobierno y a su jefe. Además, el jefe de Gobierno ejerce el poder reglamentario y nombra en los altos cargos, ya sea dentro de la administración o dentro de las empresas públicas (Hamidine 2011). El jefe de Gobierno, según la misma Constitución, se habría convertido en el verdadero jefe del poder ejecutivo. Las funciones del Consejo de Gobierno también se asemejarían a los de un auténtico Ejecutivo ${ }^{8}$.

En cambio, para otros autores la referencia al poder ejecutivo es un error que podría haberse evitado con la inclusión del rey, o conservando la tradicional mención a "la Institución Real, el Gobierno y el Parlamento" (El Mossadeq 2012). El esfuerzo que se ha realizado para ocultar el dominio de la institución real en las tareas ejecutivas no impide ver que la realidad es que la Constitución de 2011 prevé un poder ejecutivo compartido entre el Rey y el Gobierno (El Mossadeq 2012).

Dejando a un lado estas divergencias, los autores coinciden en valorar el progreso institucional de la figura del jefe de Gobierno en la Constitución de 2011, pues se partía de una presencia menor.

\footnotetext{
${ }^{6}$ Prácticamente, la competencia de nombrar y destituir al primer ministro y su Gobierno era una competencia discrecional del rey, y no estaba puesta en relación automática con los resultados electorales como está regulado ahora por el art. 47 de la Constitución de 2011 a pesar de sus defectos, esa subordinación se ve fijada y repetida en el art. 24 de todas las anteriores Constituciones desde 1962 hasta 1996, y la función del primer ministros según esas Constituciones no iba más allá de la coordinación administrativa entre los diversos ministerios cuando se lo pida (art. 65 CM 1996), en cuando a las demás competencias que tiene reconocidas por las Constituciones anteriores a 2011 tenían que ser aprobadas por el Consejo de Ministros (presidido siempre por el jefe del Estado).

7 Título V de la CM: “El Poder Ejecutivo", artículos: 87, 88, 89, 90, 91, 92, 93 y 94 CM de 2011.

8 Art. 92 CM: presidido por el jefe de Gobierno, el Consejo de Gobierno delibera sobre: la política general del Estado antes de su presentación al Consejo de Ministros; las políticas públicas; las políticas sectoriales; el compromiso de la responsabilidad del Gobierno en la Cámara de representantes; los temas de actualidad relacionados con los derechos humanos y el orden público; los proyectos de ley, incluido la ley de presupuestos, antes de su presentación en la Cámara de representantes, sin perjuicio de lo dispuesto en el artículo 49 de esta Constitución; los Decretos-leyes; los proyectos de decretos reglamentarios; los proyectos de decretos referidos en los artículos 65 (segundo párrafo), 66 y 70 (párrafo tercero) de esta Constitución; los acuerdos internacionales antes de su presentación al Consejo de ministros, el nombramiento de los secretarios permanentes y directores de la administración central, los presidentes de las universidades, decanos y directores de escuelas y colegio; la ley orgánica en virtud del artículo 49 de la presente Constitución puede completar la lista de funciones que se nombraran en el Consejo de Gobierno, y determinar los principios y criterios para el ejercicio de estos cargos, incluyendo la igualdad de oportunidades, mérito, competencia y transparencia; el jefe de Gobierno informa al Rey de los resultados de las deliberaciones del Consejo de Gobierno. (Traducción nuestra del texto oficial en árabe).
} 
En ocasiones, éste se ha convertido en auténtico poder ejecutivo, que nombra los altos cargos civiles, aunque quedan por concretar los límites derivados de las atribuciones del jefe del Estado ${ }^{9}$. En el art. $89 \mathrm{CM}^{10}$, puesto en relación con el art. $92 \mathrm{CM}$, se afirma claramente que el Gobierno ejerce el poder ejecutivo. La Constitución de 2011 impone así, una nueva cultura en la vida política en Marruecos, basada en la cooperación entre el jefe de Gobierno y el rey ${ }^{11}$, en la cual el poder del jefe de Gobierno depende en buena medida del apoyo de una mayoría parlamentaria consolidada y de la sintonía con el conjunto de fuerzas parlamentarias en general ${ }^{12}$.

\section{Las funciones del jefe de Gobierno en relación al propio poder ejecutivo}

\section{La formación del Gobierno}

Según el art. 47 CM, corresponde al Rey designar al jefe de Gobierno entre los representantes del partido político que ha obtenido más escaños en las elecciones del Consejo de representantes, y teniendo en cuenta los resultados electorales. Es el Rey también quien nombra a los demás miembros del Gobierno, pero a propuesta del jefe de Gobierno. Por ello, podría pensarse que el acto del Rey como jefe de Estado no debería ir más allá de ser un acto puramente formal. La neutralidad de la Corona favorece la idea de que la decisión de formar el Gobierno compete al jefe de Gobierno (González-Trevijano 1998). De hecho, en la primera Legislatura el Dahir ${ }^{13}$ de nombramiento de los miembros del Gobierno ha sido refrendado por el jefe de Gobierno.

Sin embargo, "la decisión del jefe de Gobierno puede ser condicionada por el resultado de las elecciones, lo que le puede obligar a formar un Gobierno de coalición, para conseguir una mayoría absoluta dentro del Consejo de representantes, sujeto a las exigencias de otras fuerzas distintas a la suya que entran en esa coalición" (Mateos de Cabo 2016). Este es el caso del primer Gobierno de Benkirane, formado por personajes que representan a cuatro partidos de ideologías distintas y cinco Ministros tecnócratas, y de ocho tecnócratas en su segundo Gobierno después de la retirada de PI (Partido de la Independencia) y sustituirlo por RNI (Rassemblement National des Indépendants) (Redouani 2004), y el mismo escenario se ha venido repitiendo en la formación del Gobierno de Al-Othmani tras las elecciones legislativas del 7 de octubre de 2016. El dominio del rey es claro en lo que se conoce como "ministerios de soberanía" por los medios de comunicación y la prensa marroquí y no se ha visto ningún cambio respecto a la anterior práctica ${ }^{14}$.

\footnotetext{
${ }^{9}$ El jefe del Gobierno nombra los altos cargos civiles según los artículos 91 y $49 \mathrm{CM}$.

${ }^{10}$ Art. 89 CM: “El Gobierno ejerce el poder ejecutivo. Bajo la autoridad del jefe de Gobierno, el Gobierno aplica su programa de Gobierno, garantiza la aplicación de las leyes, tiene la administración y supervisa las actividades de las empresas e instituciones públicas. (traducción nuestra partiendo del texto original en árabe).

${ }^{11}$ En una entrevista a Benkirane en el periódico libanés Al khabar (04/03/2013), éste afirmó sobre el tema de las relaciones diplomáticas interrumpidas entre el Reino de Marruecos y la Republica de Irán, “...compartimos con Irán relaciones históricas, la interrupción de Marruecos de sus relaciones con Irán era debida a los hechos de Bahréin, pero en lo que afecta a las relaciones exteriores, y todos los temas de la soberanía, son atribuciones de su majestad el Rey, según la nueva Constitución de Marruecos...", disponible en http://hespress.com/politique/73838.html. [Consulta: 25 de febrero de 2017].

12 Para fortalecer una mayoría estable y unida se ha creado la Comisión de la mayoría, tal como indica la carta de la mayoría gubernamental.

${ }^{13} \mathrm{El}$ Dahir (Edicto real) es un acto jurídico equivalente a una orden real, mediante el cual el Rey ejerce la mayoría de sus funciones constitucionales

${ }^{14}$ Con la excepción de los Ministerios de Justicia y Exteriores, los Ministerios del primer Gobierno de Benkirane y que estaban bajo control directo del Palacio, como ministros tecnócratas fueron nombrados Ahmed Toufiq, ministro de Habous y Asuntos Islámicos; Driss Dahak, secretario general de Gobierno; Abdeltif Loudyi, ministro delegado del jefe de Gobierno, encargado de la administración de la defensa nacional; Cherki Daris, ministro delegado del ministro de Interior y Aziz Akhannouch, ministro de Agricultura y Pesca, en un caso aislado, porque su partido político R.N.I. no ha formado parte de la primera coalición y tuvo que dimitir de su puesto como diputado del R.N.I. para ser nombrado miembro en este primer Gobierno de Benkirane.
} 


\section{La estructuración del Gobierno}

Según el art. 2 de la LOG no 065-13 de 2 abril de 2015, de acuerdo a las orientaciones del primer apartado del art. $87^{15} \mathrm{CM}$, forman el Gobierno, según el Dahir de nombramiento de sus miembros, además del jefe de Gobierno, los ministros o ministros delegados del jefe de Gobierno o de los ministros, el secretario general del Gobierno en calidad de ministro. Así, el Gobierno puede incluir también secretarios de Estado del jefe de Gobierno o de ministros ${ }^{16}$.

Según el art. 93, $2 \mathrm{CM}^{17}$, la estructura así como el número de departamentos ministeriales y en general impartir instrucciones a los demás miembros del Gobierno son competencia del jefe de Gobierno. La nueva Constitución parece así haber conferido una amplia discrecionalidad al jefe de Gobierno. En otras Constituciones y leyes fundamentales, y es la regla habitual en el ámbito europeo, se establece por Ley el número de ministros como forma de garantizar al Parlamento una prerrogativa de control sobre la organización del Gobierno. Por ejemplo, ello se encuentra previsto en la Constitución de Austria (art. 77.2) ${ }^{18}$, Grecia (art. 81) ${ }^{19}$ o Italia (art. 95) ${ }^{20}$ (mateos de Cabo 2006). En el artículo 99 de la Constitución Belga, se limita al Consejo de ministros a un máximo de quince miembros. En la Constitución de Irlanda, por su parte, se establece una horquilla entre un mínimo de siete y un máximo de quince miembros (art. 28.1) ${ }^{21}$, y en cuando a España es competencia discrecional del presidente del Gobierno ${ }^{22}$.

El jefe de Gobierno ha querido en todo caso marcar unas prioridades en cuanto a la estructura de ministerios: intentar reducir el número de ministros y sustituirlos por secretarios de Estado (Rui Ruiz 2014). Ello es debido a la voluntad de acoger el mayor número posible de candidatos presentados por sus aliados en la coalición y no tanto para facilitar el trabajo a los ministros con más cargos o más responsabilidades directivas.

A demás, el Rey ostenta la Presidencia efectiva del Consejo de ministros (art. 48, párrafo 1 CM), perpetuándose así una vía para que el Palacio siga controlando o influyendo en puestos clave del Gobierno. Por ejemplo las carteras de Economía y Hacienda, Educación, Interior, Secretaría General del Gobierno y Asuntos Exteriores han dejado de estar en manos del partido vencedor de las elecciones y su aliado $\mathrm{PI}$ y han pasado a ministros de perfil tecnocrático del RNI

\footnotetext{
${ }^{15}$ Art. 87, 1 CM2011; “El Gobierno se compone del jefe de Gobierno y de los ministros y puede incluir también a los secretarios de Estado" (Traducción de RUIZ MIGUEL, Carlos (2012), disponible en:

http://www.usc.es/export9/sites/webinstitucional/gl/institutos/ceso/descargas/Const-Marruecos-2011 es.pdf. [Consulta: 14 de junio de 2017].

${ }^{16}$ Los secretarios de Estado en caso de su existencia, forman parte de los miembros del Consejo de Ministros y deberían estar presentes en sus reuniones (art. 2 de LOG no 065 - 13), en cambio, sólo pueden asistir a un Consejo de ministros (presidido por el Rey) como invitados, porque según el art. 48,1 CM de 2011, sólo "el Rey preside el Consejo de Ministros compuesto por el jefe de Gobierno y de los ministros", traducción de RUIZ MIGUEL, Carlos, op.cit..

${ }^{17}$ Art. 93, 2 CM.: Los Ministros cumplen las misiones que tienen encomendadas por el jefe de Gobierno, informan de ello en el Consejo de Gobierno. (Traducción nuestra del texto oficial en árabe).

${ }^{18}$ Art. 77.2 de la Constitución de Austria de 1920: "Se determinarán por ley federal el número de los ministerios federales, su respectivo ámbito de competencia y su creación".

${ }^{19}$ Art. 81.1 de la Constitución de Grecia de 1975: “(...) La composición y funcionamiento del Consejo de ministros serán organizados por una ley.

${ }^{20}$ Art. 95,4 de la Constitución de Italia de 1947: "La ley proveerá a la organización de la Presidencia del Consejo y determinará el número, las atribuciones y la organización de los Ministerios".

${ }^{21}$ Art. 37 de la Constitución de Finlandia establece condiciones particulares dentro del seno gubernamental, como la de que el ministro de justicia sea una persona que posea amplios conocimientos jurídicos, como un requisito imprescindible para el desempeño de dicha función.

${ }^{22}$ Según los arts. 100 CE y 2.2 K) LG.: corresponde al Presidente del Gobierno "proponer el nombramiento y separación de los Vice Presidentes y de los Ministros". La Ley 50/1997, del Gobierno, de 27 de noviembre, ex art. 2.2.J) LG: Para "crear, modificar y suprimir, por Real Decreto los Departamentos Ministeriales, así como las Secretarias de Estado".
} 
(Rassemblement National des Indépendants) o figuras independientes ${ }^{23}$ y de confianza del rey. La práctica de los «ministerios de soberanía» según parece ha tenido continuidad pese a todo.

\section{El liderazgo del Consejo de Gobierno}

Las competencias del Consejo de Gobierno parecen amplias, pues es un órgano que delibera y toma decisiones sobre las políticas públicas y sectoriales del Estado, la relación con el Parlamento y otras instituciones y la competencia de nombramiento de altos cargos. Ciertamente, algunas de estas competencias se encuentran reservadas al Consejo de Ministros, pero la configuración constitucional de este Consejo de Gobierno es una novedad destacable de la Constitución de 2011.

Como siempre, será la práctica política y la aplicación de la Ley Orgánica de Gobierno prevista en el art. 87, 2, es decir la ley no 065-13, la que acabará precisando las competencias del Consejo de Gobierno. Será importante valorar la frecuencia con que tienen lugar las sesiones de este órgano bajo presidencia del jefe de Gobierno. Es significativo que el art. $92 \mathrm{CM}$, in fine, disponga que "el jefe de Gobierno informa al Rey de las conclusiones de las deliberaciones del Consejo de Gobierno". Es decir, le facilita conocimientos, al igual como el primer ministro inglés informa a la reina de las decisiones políticas adoptadas por su Gobierno todas las semanas. Nadie puede prever cuáles serán las consecuencias de esa información, pero es una muestra de las distintas funciones reservadas al Rey y al Gobierno. Desde un punto de vista jurídico, la Constitución es bastante imprecisa respecto a los poderes del Gobierno en comparación con otras Constituciones ${ }^{24}$.

Los artículos 90 y $91 \mathrm{CM}$ resumen lo esencial de la función ejecutiva: "el jefe de Gobierno ejerce el poder reglamentario (...)" y “(...) puede delegar algunos de sus poderes a los ministros". "Los actos (...) son refrendados por los ministros encargados de su ejecución", y "el jefe de Gobierno nombra a los cargos civiles de las administraciones públicas y a los altos cargos (...)". El apartado segundo del art. 89 precisa que "bajo la autoridad del jefe de Gobierno, el Gobierno ejecuta su programa (...)". Ello constituye el fundamento de un verdadero poder de dirección política, y debería permitir al jefe de Gobierno llevar a cabo este cometido (Maus 2012). Por todo ello, no hay duda de que el poder gubernamental ha sido teóricamente confirmado, pero siguen habiendo ambigüedades.

\footnotetext{
${ }^{23}$ RUIZ RUIZ, J.J. (2014): "La Constitución marroquí de 2011 y el ensayo de parlamentarización de la monarquía", Revista de Estudios Políticos, Núm. 164, abril-junio, p. 56.

${ }^{24}$ El título III dedicado al Gobierno en la Constitución francesa de 1958 es más corto, contiene sólo 4 artículos, pero en cambio reconoce más poder al primer ministro:

“Art. 20: El Gobierno determinará y dirigirá la política de la Nación. Dispondrá de la Administración y de las fuerzas armadas. Será responsable ante el Parlamento en las condiciones y conforme a los procedimientos establecidos en los artículos 49 y 50.

Art. 21: El primer ministro dirigirá la acción del Gobierno. Será responsable de la defensa nacional. Garantizará la ejecución de las leyes. Sin perjuicio de lo dispuesto en el artículo 13, ejercerá la potestad reglamentaria y nombrará en los cargos civiles y militares. Podrá delegar algunos de sus poderes a los ministros. Suplirá, en caso necesario, al presidente de la República en la presidencia de los consejos y de los comités a que se refiere el artículo 15. Podrá, a título excepcional, suplir al presidente de la República en la presidencia de un Consejo de ministros en virtud de una delegación expresa y con un orden del día determinado.

Art. 22: Las decisiones del primer ministro serán refrendadas, en su caso, por los ministros encargados de su ejecución.

Art. 23: Son incompatibles las funciones de miembro del Gobierno con el ejercicio de todo mandato parlamentario, de toda función de representación de carácter nacional y de todo empleo público o actividad profesional. Una ley orgánica fijará el modo de sustitución de los titulares de tales mandatos, funciones, o empleos. La sustitución de los miembros del Parlamento se efectuará conforme a lo dispuesto en el art. 25". 
El Rey conserva buena parte de su poder mediante la presidencia del Consejo de ministros y gracias a las competencias del mismo, previstas en el art. 49 CM. Este Consejo delibera sobre las cuestiones más importantes. En caso de discrepancias, no queda claro si se impone la opinión mayoritaria o incluso unánime cuando ésta sea contraria al parecer del Rey. El art. 49 CM de 2011, reza como sigue: “(...) El Consejo de ministros delibera sobre: Las orientaciones estratégicas de la política del Estado, los proyectos de revisiones constitucionales, los proyectos de leyes orgánicas, los proyectos de ley-marco (...), el proyecto ley de amnistía, los proyectos de leyes relativos a la Administración militar, la declaración del Estado de sitio o de bloqueo, la declaración de guerra, el proyecto de decreto previsto en el art. 104 relativo a la disolución del Consejo de representantes, a iniciativa del jefe de Gobierno, el nombramiento, a propuesta del jefe de Gobierno, y a iniciativa del ministro encargado, en los altos cargos civiles (...).

Resumiendo, el Consejo de ministros tiene atribuidas las competencias políticas, estratégicas y simbólicas más importantes. El Consejo de ministros, presidido por el Rey, determina las orientaciones estratégicas generales del Estado, mientras que el Consejo de Gobierno, presidido por el jefe de Gobierno, delibera sobre las propuestas que serán posteriormente presentadas al primero, y después, pone en práctica las políticas públicas y las políticas sectoriales. Asimismo, el Consejo de Gobierno es un órgano regular mientras que, según puede leerse en el art. 48,2 CM "el Consejo de ministros se reúne a la iniciativa del Rey o a petición del jefe de Gobierno". De este modo, el Consejo de ministros no se reúne de manera regular o periódica, y requiere normalmente una estrecha consulta entre el jefe del Gobierno y los colaboradores cercanos al Rey, o con el Rey en persona. En definitiva, durante la vigencia de la actual Constitución de 2011 no se ha celebrado ningún Consejo de ministros bajo la presidencia del jefe de Gobierno.

\section{Una cohabitación desequilibrada}

La gestión gubernamental del Partido Justicia y Desarrollo (PJD), en sus dos etapas, enero de 2012 y octubre de 2013, se puede considerar un supuesto de doble cohabitación. "Por un lado una cohabitación en el seno del Gobierno derivada de la formación de un Ejecutivo de coalición ideológicamente heterogéneo, muy extenso y sometido a tensiones recurrentes entre sus miembros derivadas de la falta de cohesión interna y de las interferencias del Majzén" (Hernando de Larramendi 2013).

A esta complicada cohabitación en el interior del Gobierno hay que añadir otra derivada de las relaciones con Palacio y el Majzén. Aunque la nueva Constitución presenta una hoja de ruta para la separación de poderes, "el Rey sigue controlando las áreas claves de la vida pública en una infracción clara al nuevo texto fundamental. Las diferencias en el seno del ejecutivo han dificultado la capacidad del Gobierno para reforzar su autonomía frente al Majzén y han permitido al Rey seguir manteniendo, de facto, su papel central en el sistema político" (Hernando de Larramendi 2013). Lo ha hecho interviniendo en el nombramiento de los embajadores (anouzla 2013), walis y gobernadores así como en la designación de los miembros de instituciones públicas como el Tribunal de Cuentas, el Consejo Económico y Social y de instancias como la Comisión de Reforma de la Justicia (Desrues 2013), Consejo Superior de Educación, de la Formación y de la Investigación Científica ${ }^{25}$, e inaugurando los grandes proyectos del Gobierno o creando comisiones

\footnotetext{
${ }^{25}$ El Consejo Superior de Educación, de la Formación y de la Investigación Científica es un Consejo de asesoramiento sobre la de Reforma del Sistema Educativo en Marruecos, es totalmente autónomo de los ministerios competentes. Todos sus miembros fueron designados de forma directa o indirecta por el Monarca, el consejero real Omar Azziman
} 
de investigación, sin previa consulta con el jefe del Gobierno. También lo hace indirectamente a través de los miembros del Gabinete Real a los que la Constitución no atribuye ningún papel formal pero que juegan un destacado papel público.

Se desprende de lo anterior que las competencias del Gobierno no le permiten determinar ni dirigir la política general de la Nación con total independencia del Rey, de manera que, por una parte el jefe de Gobierno debe tener en cuenta a la hora de elaborar su programa político las orientaciones estratégicas decididas en Consejo de Ministros, mientras que por otra parte el Consejo de Ministros es la institución en la que el Rey informa a los miembros del Gobierno sobre las decisiones adoptadas por él y que no podrán ser objeto de discusión o de reserva (Ruiz Ruiz 2014).

\section{El poder de refrendo}

La función de refrendar los Dahires reales es la técnica que ejemplifica mejor la colaboración y la cooperación, y que hace que el jefe de Gobierno participe en la función ejecutiva. Además, el refrendo refuerza la institución del jefe de Gobierno en el sistema constitucional marroquí.

El Dahir es un acto jurídico equivalente a una orden real, mediante el cual el Rey ejerce la mayoría de sus funciones constitucionales. Literalmente significa "el apoyo y el respaldo", y se usa en varios párrafos del Corán. Su régimen jurídico es distinto de las resoluciones administrativas cuya competencia recae sobre la sala administrativa del Consejo Superior de Justicia ${ }^{26}$. El Rey ejerce sus funciones relacionadas con la dirección del poder ejecutivo con Dahires refrendados por el jefe de Gobierno, salvo excepción expresa. Entonces, ¿estaría el jefe de Gobierno obligado a refrendar los Dahires reales?

En el art. 42 CM puede leerse que “(...) el Rey ejerce sus atribuciones mediante Dahires dentro del poder que le reconoce la presente Constitución. Los Dahires, excepto los indicados en los artículos $41 \mathrm{CM}, 44,2 \mathrm{CM}, 47,1-6 \mathrm{CM}, 51 \mathrm{CM}, 57 \mathrm{CM}, 59 \mathrm{CM}, 130,1-4 \mathrm{CM}$ y $174 \mathrm{CM}$, son refrendados por el jefe de Gobierno". Se desprende de la literalidad del art. 42 CM que hay Dahires, previstos en la Constitución, que no necesitan ser refrendados por el jefe de Gobierno, y otros que necesitan serlo. Entre los Dahires que no necesitan ser refrendados encontramos los que son necesarios para el ejercicio de las funciones encomendadas a las instituciones constitucionales y otros que están relacionados con la función arbitral del Rey. Todo Dahir cuyo contenido no sea el referido en el art. 42 CM debería, a sensu contrario, ser refrendado por el jefe de Gobierno. El Dahir de nombramiento de los consejeros reales no está incluido en el listado del art. $42 \mathrm{CM}$ y por tanto lo razonable sería respetar el texto constitucional de 2011 con el fin de reforzar la Institución del jefe de Gobierno. Si el jefe de Gobierno refrenda el Dahir de nombramiento de los ministros que tienen funciones constitucionales claras e importantes, lo lógico sería que el jefe de Gobierno refrendase también los Dahires de nombramiento de los consejeros de la casa real, pero ello no se da en la práctica.

Los Dahires que sí necesitan ser refrendados por el jefe de Gobierno vendrían a ser entonces:

- $\quad$ El nombramiento de los miembros del nuevo Gobierno, y poner fin a sus funciones (art. 47 $\mathrm{CM}$, segundo, tercero y cuarto párrafo).

\footnotetext{
fue nombrado su presidente por Dahir, el Consejo fue creado por la ley no 105-12, el 16 de mayo de 2014 , para sustituir al anterior Consejo Superior de Educación.

${ }^{26}$ Sentencia de la Sala Administrativa del Consejo Superior de Justicia en el famoso caso de «Al-Ruanda Abdel Hamid» del 18 de junio 1960. Sentencia de la Sala Administrativa del Consejo Superior de Justicia en el famoso caso de «La Empresa campesina conocida por la Granja de Abdel Aziz " del 18 y 20 de marzo de 1970.Sentencia de la Sala Constitucional (el Tribunal Constitucional en actualidad en la Constitución de 2011) no 61, del 5 de mayo de 1971.
} 
- $\quad$ Dahires de publicación de la ley con orden de ejecutarla (art. 50 CM).

- $\quad$ Dahires para la validación de los tratados internacionales (art. 55, 2 CM).

- $\quad$ Dahires de la Gracia (art.58 CM).

- $\quad$ Dahir de declaración del Estado de bloqueo (art. 74 CM).

- $\quad$ Dahires de nombramientos de altos cargos (art.92 CM).

- $\quad$ Dahires relacionados con la función de la defensa nacional (art. 53 CM).

- $\quad$ Dahir de declaración de guerra (art.99 CM).

En resumen, los Dahires que no necesitan ser refrendados son diez, mientras los que necesitan serlo son ocho. Ello muestra, como avanzábamos, que el Ejecutivo actúa sobre una base participativa o de colaboración entre el jefe de Gobierno y el Rey. Los Dahires refrendados por el jefe de Gobierno son los más utilizados, como el Dahir con orden de ejecutar la ley, por ejemplo.

Cabe señalar que los Dahires que quedan exentos del refrendo son en su mayoría de carácter político o religioso, e infrecuentes, mientras que los Dahires que refrenda el jefe de Gobierno son habituales y de uso administrativo y repetido.

\section{El poder reglamentario Los protagonistas del poder reglamentario}

El poder reglamentario en Marruecos es un poder que depende directamente de la potestad ejecutiva, y que no solo debe asegurar la ejecución de la ley, sino que permite tomar aquellas medidas reglamentarias absolutamente necesarias, incluso en ausencia de previsión legal. Se reconoce, por consiguiente, no solo el reglamento ejecutivo de ley previa, sino también el reglamento autónomo o independiente, fundamentado en una potestad reglamentaria con legitimidad sustantiva y directa, no derivada.

Pues bien, no conceder al jefe de Gobierno el poder reglamentario imposibilitaría el normal funcionamiento de su capacidad de dirección de la Administración Pública. Por ello resulta interesante valorar la práctica del ejercicio de dirección del aparato administrativo para comprobar el uso efectivo o no del poder reglamentario por parte del jefe de Gobierno.

Según reza el art. 90 CM, "El jefe de Gobierno ejerce el poder reglamentario, y puede delegar algunas de sus funciones a los ministros. Los actos reglamentarios del jefe de Gobierno son refrendados por los ministros encargados de su ejecución". Añade el art. 72 CM, "los asuntos no incluidos en el ámbito de la ley entran en el dominio reglamentario". De este marco constitucional se deducen los siguientes criterios generales:

A - No parece existir ningún cambio en cuanto a la potestad reglamentaria del jefe de Gobierno en relación a los textos constitucionales históricos desde 1962.

B - El jefe de Gobierno es el único que puede ejercer el poder reglamentario, mientras los ministros no disponen de tal facultad.

$\mathrm{C}$ - Las materias determinadas en el art. $71 \mathrm{CM}$, y que son funciones propiamente legislativas, no deben ser ejercidas por el jefe de Gobierno, pues no pertenecen al ámbito reglamentario.

D - El Gobierno en su conjunto, bajo la autoridad del jefe de Gobierno, es responsable de la ejecución de las leyes. 
En definitiva, la Constitución de 2011 ha atribuido todo el poder reglamentario, sea éste autónomo $^{27}$ o ejecutivo ${ }^{28}$, al jefe de Gobierno, mientras reserva al Rey ámbitos concretos. Así, el Monarca, de acuerdo con el párrafo quinto del art. $41 \mathrm{CM}$, "(...) ejerce las funciones religiosas relacionadas con su condición de Rey "Amir al Muminin" -comendador de los creyentes, título religioso- (Parejo y Feliu 2013), y tiene competencia exclusiva para adoptar Dahires sobre el mismo". Asimismo, según reza el párrafo tercero del art. 42 CM, “(...) el Rey, realiza estas funciones mediante Dahires, tal como establece esta Constitución (...)", eso le permite usar el mecanismo del dahir de forma expansiva en el ámbito religioso, y es cierta la apreciación que hace Melloni, cuando recuerda que los dahires que intervienen en asuntos religiosos en la práctica vienen teniendo como campo de acción el derecho privado y en especial el derecho de familia (Melloni 2012). Finalmente, puede leerse en el art. 53 CM que "el Rey es el Jefe supremo de las Fuerzas Armadas Reales (FAR), nombra a los altos cargos militares y puede delegar este derecho", y eso afecta de forma muy clara a la subordinación de las Fuerzas Armadas Reales al poder reglamentario del jefe de Gobierno.

Volviendo al contenido del texto Constitucional de julio de 2011, veremos que esta Constitución no distingue de forma clara entre los decretos autónomos y los ejecutivos. La jurisdicción ordinaria tampoco ha utilizado ninguno de estos dos términos. En cuanto a la jurisdicción constitucional en Marruecos, suele utilizar la expresión "el dominio reglamentario". En la doctrina francesa es unánime el reconocimiento a un único poder reglamentario, sin diferencias por razón del carácter autónomo o ejecutivo del decreto adoptado.

\section{La delegación del poder reglamentario}

El jefe de Gobierno conserva varias importantes funciones, pues según reza el art. $90 \mathrm{CM}$, "el jefe de Gobierno ejerce el poder reglamentario y puede delegar algunos poderes a ministros. Los actos reglamentarios del jefe de Gobierno son refrendados por los ministros encargados de su ejecución". Completa lo anterior el art. 91 CM cuando añade "el jefe de Gobierno nombra a los cargos civiles de las administraciones públicas y los altos cargos de las instituciones y empresas públicas (...). El jefe de Gobierno puede delegar este poder".

Pues bien, este marco normativo permite avanzar en primer lugar, y como principio general, que es el jefe de Gobierno quien puede ejercer el poder reglamentario, pero también puede delegar parte de su poder a los ministros. Esto fue confirmado también por el art. 7 de LOG 065-13: "de acuerdo con las disposiciones del primer apartado del art. $90 \mathrm{CM}$, el jefe de Gobierno puede delegar, con decreto, algunos de sus poderes a los ministros". Añade el art. 10 de la misma LOG,

\footnotetext{
${ }^{27}$ Entendemos por poder reglamentario autónomo el conjunto de los actos, decisiones y decretos que no están amparados en ninguna Ley, ni ejecutan o aplican alguna ley. El jefe de Gobierno, según el art. 90 CM, ejerce este poder reglamentario autónomo. En la misma línea, en el art. $72 \mathrm{CM}$ puede leerse que "las materias que no pertenecen al ámbito de la ley, pertenecen al dominio reglamentario". El jefe de Gobierno ejerce concretamente el poder reglamentario mediante Decretos.

${ }^{28} \mathrm{El}$ poder reglamentario ejecutivo es un mecanismo ordinario en el procedimiento de poner un texto legislativo en práctica, mediante "reglas detalladas, necesarias para facilitar la ejecución de la Ley, (...) y el motivo de este detalle, es porque gran parte de las Leyes adoptadas por el Parlamento suelen establecer normas y reglas sin entrar en los efectos y los detalles que suelen cambiarse continuamente; el segundo motivo es para reducir la carga legislativa de la institución parlamentaria, de manera que ésta pueda centrarse en los principios y las cuestiones más importantes". Así, la adopción de un decreto ejecutivo requiere la existencia de una ley previa, y la función del primero consiste en "detallar y explicar (...), y concretar procedimientos allí donde la ley solo ha puesto principios". En este sentido, según el art. 89 CM, segundo párrafo: "bajo la autoridad del jefe de Gobierno, el Gobierno pone en obra su Programa Político, asegura la ejecución de las leyes, dirige la administración y supervisa los organismos y empresas públicas y asegura su tutela sobre ellos". (Traducción de RUIZ MIGUEL, Carlos, Op. cit.)
}

44 
pero ésta vez en referencia a las nuevas atribuciones de los ministros delegados: "Los ministros delegados pueden recibir, según el caso, del jefe de Gobierno o de los ministros a los que se delegan, delegación de atribuciones o de firma. Las delegaciones de estas atribuciones pueden llevar al refrendo de los actos reglamentarios del jefe de Gobierno, pero en este caso, los decretos de delegaciones de los Ministros deben ser aprobados por el Jefe de Gobierno antes de ejecutarlas". Según el último apartado del art, 11 LOG, la misma norma es aplicable en relación a los decretos de delegación a los secretarios de Estado. Es decir, cualquier delegación de poder reglamentario a los secretarios de Estado tiene que ser aprobada por el jefe de Gobierno.

Otro aspecto importante, es que los ministros refrendan los decretos reglamentarios procedentes del jefe de Gobierno. Por otro lado, la Constitución parece reservar el refrendo a los ministros, y no así a los secretarios del Estado. Ello parece coincidir además con la jurisprudencia del Consejo del Estado Francés. Los ministros también participan en el poder reglamentario junto al Jefe de Gobierno. Ello acontece por dos vías: por la iniciativa en la propuesta del texto reglamentario y por su refrendo.

\section{Las competencias del Gobierno sobre la definición de la estrategia militar del Estado}

En lo que concierne a las competencias del Gobierno en materia de definición de la estrategia militar del país, la Constitución de 2011 ha reforzado las competencias del Gobierno en algunos sectores. Sin embargo, la política de defensa continúa siendo competencia exclusiva del jefe del Estado, y no específica, sin embargo, si el Gobierno tiene la obligación de responder ante el Parlamento sobre algún tema relacionado con este sector. Ello se debe, simplemente, a que no tiene ninguna autoridad sobre las Fuerzas Armadas Reales (FAR).

El Ministro delegado encargado de la Administración de la defensa nacional ${ }^{29}$ es responsable de la gestión administrativa de las FAR. Ello no incluye, entre otras, ni la planificación de las capacidades estratégicas, ni la creación de una fuerza armada, ni la gestión de los programas de defensa y planificación de actividades en marcha (Saaf 2011). El jefe de Gobierno está presente en el Consejo Superior de Seguridad (CSS), según el art. 54 CM, e incluso puede presidirlo, con la debida delegación del Rey pero sobre la base de un orden de día determinado.

La Constitución establece como regla general el principio de la dirección civil. Por lo tanto, las decisiones que afectan a la defensa nacional y las fuerzas armadas en el territorio de Marruecos o en el exterior, deberían ser tomadas por políticos responsables ante el Parlamento, y no por militares. Además, la Constitución prevé el equilibrio entre los poderes y el control sobre el Gobierno, las fuerzas armadas y la administración pública. En la práctica, sin embargo, no son los miembros del Gobierno quienes determinan la política de defensa. El Rey es quien dirige la Administración general de la defensa y quien decide sus grandes orientaciones estratégicas. Su preeminencia se debe a que la delegación de sus competencias al Gobierno sigue siendo limitada. Más allá del poder reglamentario de que dispone el Gobierno, en virtud del art. 90 de la Constitución, en el marco de unas cuantas circunstancias relativas a la declaración de guerra o del Estado de sitio, ni el jefe de Gobierno ni los demás miembros de su Gobierno ejercen hasta este momento un control real sobre las Fuerzas Armadas (Saïdy 2012).

Por otro lado, el establecimiento de un control democrático del poder civil sobre las fuerzas armadas requiere un departamento ministerial con autoridad y competencias suficientes, en el

\footnotetext{
${ }^{29}$ El ministro delegado del jefe del gobierno para la administración de la defensa nacional ejerce sus atribuciones en virtud de la delegación que de esta materia efectuó el Monarca mediante el dahir no 1.07.203, de 30 de noviembre de 2007 (B. O. no 5583 de 3 de diciembre de 2007).
} 
marco general del funcionamiento del gobierno, para hacer pública la política de defensa y comenzar una reforma que implica la responsabilidad jerarquía de la armada cara a cara con el poder ejecutivo. Desde la creación, en 1997, del cargo de ministro delegado del primer ministro que se convirtió en jefe de Gobierno en la Constitución de 2011 - encargado de la administración de la defensa nacional, este puesto siempre fue ocupado por un civil. En este contexto de transformación y desarrollo político, el cambio de este estatus al de un ministro de defensa nacional, le permitiría tener un papel de mediador entre los diferentes órganos decisivos en la materia, en particular tras la creación del CSS. Eso permitiría igualmente una mejor gobernanza de la defensa, conciliando las necesidades y limitaciones presupuestarias y, en definitiva, definiendo la estrategia militar (Saïdy 2012, p. 10).

Sin embargo, tras la creación del CSS, órgano completamente autónomo del Gobierno y solo dependiente del Rey, que priva del mando de las fuerzas armadas al Ministerio delegado para la administración de la Defensa nacional (Ruiz Miguel 2012), sigue sin corregirse la anormalidad institucional de no contar con un verdadero Ministerio. Esta situación se viene prolongando durante más de 45 años desde que se suprimió el Ministerio de Defensa tras los dos intentos de golpe de Estado de 1971 y 1972. La creación de este ministerio ha sido defendida por parte de la doctrina (Desrues 2007).

El problema no reside solamente en el texto constitucional, equiparable a grandes rasgos a lo previsto al respecto en otros países democráticos. El mayor reto está en la aplicación de este texto y en la práctica política. Sin embargo, en esa práctica, los militares y los civiles no han culminado un modelo de trabajo en común. Los primeros sienten que son responsables únicamente ante el Rey y tienen una actitud de desconfianza en relación a los políticos ${ }^{30}$. Por su parte, los civiles no se interesan por los asuntos militares para evitar cualquier tipo de conflicto, y lo consideran un asunto reservado al Rey. Existe así una separación rígida entre los sectores civil y militar (Saïdy 2012, p. 169).

El principio de la supremacía del poder civil o del Gobierno sobre el poder militar, previsto en la Constitución debería ser, en la práctica, confirmado por una "responsabilidad compartida", mediante un funcionamiento armonioso de este sector. Ello exige que las fuerzas armadas se sumen a las transformaciones sociales y que los oficiales superiores armonicen sus principios con la cultura democrática. Ello les permitiría participar activamente en una buena gobernanza de la seguridad nacional, que es un objetivo compartido por todos (Saïdy 2012, p. 170).

\section{Las funciones del jefe de Gobierno en relación a los demás poderes del Estado en el texto fundamental de 2011}

\section{En relación al poder legislativo}

Con la nueva Constitución, parece que el jefe de Gobierno ha sumado nuevas competencias al conjunto de sus funciones. Algunas de ellas han sido ya estudiadas, como es el caso de la participación del jefe de Gobierno en la investidura, en la moción de censura, en el refrendo, en la sanción y promulgación de las leyes (Saïdy 2012, p. 169). Las otras principales funciones relacionadas con la potestad legislativa, expuestas de forma esquemática son:

\footnotetext{
30 "Los altos cargos en la jerarquía militar en Marruecos, durante el reino de Hassan II y en los primeros años de Gobierno de Mohamed VI, además de sus puestos militares han dirigido Administraciones y establecimientos públicos de esfera civil y se han beneficiado de títulos, licencias de carácter económico y propiedades, además de una influencia e inmunidad no explicada" (Wald Akabla 2009).

46
} 
- Proporcionarle al jefe del Estado el asesoramiento sobre el estado de excepción, junto con el presidente del Tribunal Constitucional y los presidentes de las dos Cámaras legislativas (art. 59 CM).

- Refrendar el Dahir de declaración del estado de emergencia o bloqueo y que pueden paralizar la institución del Parlamento, pero sin disolver ninguna Cámara (art. 74 CM).

- Dictar el Decreto que da por concluida la Legislatura, cuando ésta ha durado cuatro meses como mínimo (art. 65 y $92 \mathrm{CM}$ ).

- Cada Cámara del Parlamento puede reunirse en secreto a petición del jefe de Gobierno, y con los Comités de las dos Cámaras parlamentarias (art. 68, 2 CM).

- Solicitar a los presidentes de las dos Cámaras del Parlamento convocar reuniones conjuntas, de ambas Cámaras para presentar información sobre casos de carácter nacional importante (art. $68 \mathrm{CM})$.

- Responder en persona a las preguntas sobre la política general de su Gobierno (art. 103,3 $\mathrm{CM})$.

- Presentar ante el Parlamento una revisión del progreso de la acción gubernamental, a iniciativa propia o a petición de un tercio de los miembros del Consejo de representantes o de la mayoría absoluta de los miembros de la Cámara de consejeros (art. 101 CM).

- Comprometer, en su caso, la responsabilidad del Gobierno en el Consejo de representantes, sobre una declaración de política en general, o un voto sobre un texto de un proyecto de ley (art. $103,1 \mathrm{CM})$.

- Disolver la Cámara de representantes -la Cámara Baja- por Decreto del Consejo de Ministros, previa consulta al Rey, al presidente de la Cámara de representantes y al presidente del Tribunal Constitucional. En este caso, también debe presentar en la misma Cámara una declaración indicando los motivos de esta decisión (art. 104 CM).

- Responder en plazo de seis días al desafío de la Cámara de consejeros. La respuesta debe ser acompañada de un debate, pero sin votación (art. 106 CM).

Además, a la vista de las relaciones entre el poder ejecutivo y el poder legislativo, el jefe de Gobierno dispone de una serie de prerrogativas, unas son perfectamente usuales, otras pertenecen más a los que se suele llamar "parlamentarismo racionalizado". Así que:

- En virtud del art. $78 \mathrm{CM}$, el jefe de Gobierno, después de una deliberación del Consejo de Gobierno, tiene atribuida la iniciativa legislativa.

- Según el art. 79 CM, puede oponerse a las propuestas de enmiendas que no son del dominio de la ley, tal como se ha determinado por el art. $71 \mathrm{CM}$.

- Puede también, de acuerdo al art. 77 CM, él mismo o a través de uno de sus ministros, oponerse a las iniciativas parlamentarias que afecten al equilibrio presupuestario.

- El art. 81 restaura, dentro del período de sesiones del Parlamento, un procedimiento de Decreto-Ley a la disposición del Gobierno, pero sujeto a las formalidades de ratificación rápida. 
- Inspirada en la práctica francesa, el art. 82,1 CM asigna al Gobierno una prioridad en el orden del día de las asambleas.

- De igual manera, el art. $83 \mathrm{CM}$ le da derecho de enmienda y le permite, a través de su apartado 20 , implementar un procedimiento de voto bloqueado para evitar la desnaturalización de los proyectos de ley ${ }^{31}$.

A nuestro punto de vista, lo que es nuevo a nivel del ejercicio de esas funciones, es: desde la creación constitucional de la Institución del Consejo de Gobierno por primera vez en 2011, gran parte de ellas ya no necesitan ser aprobadas necesariamente dentro del Consejo de Ministros, sobre todo cuando no se trata de actos importantes o de decisiones sobre temas estratégicos en la política legislativa del Estado, pero siempre se harán preguntas sobre la línea de separación entre el dominio de las dos instituciones del poder ejecutivo, el Consejo de Gobierno presidido por el jefe de Gobierno de un lado, y del Consejo de Ministros presidido por el Rey, sobre todo a nivel de su participación legislativa o en su relación con la propia institución parlamentaria.

\section{En relación al poder judicial}

El poder judicial se encuentra regulado en el Título VII de la Constitución de julio de 2011. Según el texto constitucional, parece que se ha convertido en un Poder independiente del Poder ejecutivo y autónomo. Su órgano más alto es el Consejo Superior (Supremo) del Poder Judicial (CSPJ), y es el único órgano con la función de designar a los jueces (art. $57 \mathrm{CM}$ ). El nombramiento formal debe ser realizado por el Rey mediante Dahir que no debería ser refrendado ni por el jefe de Gobierno ni por el ministro de justicia (art. 42,4 CM).

Para garantizar aún más esta autonomía, el constituyente ha dedicado su protección a la Institución Real (art. 107 CM). La reforma más profunda en nuestra opinión la encontramos en el segundo párrafo del artículo 116 CM: se le reconoce al Consejo Superior del Poder Judicial, por primera vez, la autonomía administrativa y financiera. Por ello, la relación entre el poder judicial y el poder ejecutivo presidido por el jefe de Gobierno, sólo tiene lugar, mediante la labor de la fiscalía general, bajo control e indicaciones jurídicas por escrito del ministro competente (art. $110,2 \mathrm{CM})$.

Es cierto que la Constitución de 2011 habla, por primera vez, de "separación de poderes" (art. 1, $2)^{32}$ y añade algo que ya se decía en el texto anterior, a saber que el poder judicial es autónomo e "independiente" de los poderes ejecutivo y legislativo (art. 107, 1, cláusula parecida a la del art. 82 de la Constitución de 1996). Sin embargo, no dice que sea "independiente" del poder del Rey, al que están subordinados, los tres poderes clásicos del Estado. El control del Rey opera tanto en el acceso a la judicatura como una vez dentro de la misma.

El acceso a la judicatura depende de una decisión libre del Rey. El art. 57 de la Constitución establece que "el Rey aprueba por Dahir el nombramiento de los magistrados del Consejo Superior del Poder Judicial". Es muy importante advertir que, según el art. 42, 4 CM estos dahires no requieren del refrendo del jefe del Ejecutivo.

\footnotetext{
${ }^{31}$ Art. 83,2 CM: "Si el Gobierno lo pide, la cámara donde está el texto en discusión, decidirá con un solo voto sobre su totalidad o parte de él, reteniendo sólo las enmiendas propuestas o aceptadas por el Gobierno. Esa Cámara podrá oponerse a este procedimiento, pero solo con el voto de la mayoría de sus miembros".

${ }^{32}$ Art. 107, 1 CM de 2011: "El poder judicial es independiente del poder legislativo y del poder ejecutivo". 48
} 
Una vez se ha accedido a la judicatura, no por ello finaliza el ascendente, en este caso indirecto, del Rey. El art. 113, 1 CM estipula que "el Consejo Superior del Poder Judicial vela por la aplicación de las garantías otorgadas a los magistrados, en especial en cuanto a su independencia, su propuesta de nombramiento, su ascenso, su jubilación y su disciplina". Ya la Constitución de 1996, en su art. 86, reconocía un "Consejo Superior de la magistratura" (CSM), con cierta similitud estructural con el nuevo "Consejo Superior del Poder Judicial" (CSPJ). Ahora bien, este CSPJ que debe velar por las "garantías" otorgadas a los jueces está controlado por el Rey. En efecto, de acuerdo con el art. 115 de la nueva Constitución el CSPJ, que preside el propio rey, se compone de 20 miembros además del Rey (art. 56) ${ }^{33}$. Pues bien, 10 de esos miembros son designados directo o indirectamente por el Rey. Uno de entre esos 10 miembros designados por el Rey preside el CSPJ por delegación del rey.

\section{En relación al poder corrector}

El Tribunal Constitucional tiene la atribución de revisar la adecuación de las leyes, los proyectos de ley y los Decretos del poder ejecutivo, a la Constitución ${ }^{34}$.

Y específicamente, la relación del jefe de Gobierno con el Tribunal Constitucional en Marruecos, se sustancia en los siguientes actos:

- El jefe de Gobierno puede presentar cualquier tratado internacional ante el Tribunal Constitucional para decidir sobre su constitucionalidad, antes del trámite de ratificación parlamentaria (art. $55 \mathrm{CM}$ ).

- Con el mismo fin, puede remitir leyes antes de su promulgación al Tribunal Constitucional para que éste decida sobre su constitucionalidad (art. 132 CM).

- El jefe de Gobierno puede pedir del Tribunal Constitucional que resuelva sobre la disputa o el desacuerdo entre su Gobierno y cualquier Cámara Legislativa (art. 79 CM).

- Y por fin, debe acatar las decisiones de este Tribunal sin poder presentar ningún tipo de recurso al respecto, igual que todas las demás autoridades administrativas y jurídicas (art. 134,2 $\mathrm{CM})$.

Es importante señalar que en el texto original del proyecto de la Constitución publicado el 17 de junio de 2011 en el BO no 5952 Bis, fue rectificado solo un día antes del día del referéndum y se publicó finalmente en el BO no 5956 del día 30 de junio de 2011, "como rectificación de un error material en el Boletín Oficial número 5952 Bis, del día 17 de junio de 2011. Después de esta corrección el Dahir de nombramiento del presidente del Tribunal Constitucional "no requiere ningún refrendo".

Pero, parece que la subordinación directa de la institución del Tribunal Constitucional y del CSPJ mencionado en el anterior apartado al jefe del Estado, sobre todo a nivel de nombramiento de sus presidentes y de la mayoría de sus miembros, desmienten toda "propaganda" en defensa de lo que se ha proclamado como si fuera el inicio de una transición profunda y una apuesta por el respecto del principio de separación de poderes.

\footnotetext{
33 Art. 56 CM de 2011: "El Rey preside el Consejo Superior del Poder Judicial”.

${ }^{34}$ Art. 132,1 CM.: además "El Tribunal Constitucional ejerce las funciones que le confieren las disposiciones de la Constitución y las disposiciones de las leyes orgánicas. Inteviene también en la regularidad de la elección de los miembros del Parlamento y las operaciones de referéndum" (Traducción directa del texto oficial en árabe).
} 
¿Cómo se ha podido afirmar entonces en el primer artículo de la reciente Constitución ${ }^{35}$ que hay una separación de poderes dentro de un sistema monárquico tradicional, cuando ningún poder ha quedado fuera del dominio directo del Rey?

\footnotetext{
${ }^{35}$ Art. 1 de CM 2011: “Marruecos es una monarquía constitucional, democrática, parlamentaria y social. El régimen constitucional del Reino está fundado sobre la separación, el equilibrio y la colaboración de Poderes..." (Traducción de RUIZ MIGUEL, Carlos, 2012). 


\section{Reflexiones finales}

El jefe de Gobierno pre-constitucional era únicamente un primus inter pares, el primero entre los ministros. Su función principal consistía en coordinar la actuación del Gobierno. En cambio, no puede decirse de la institución pre-constitucional que fuese el auténtico protagonista en el Consejo de ministros (arts. 88,2 y 93,2 CM), ni que representase plenamente al Gobierno, ni tampoco que tuviera la capacidad política para dotar autónomamente de contenido al programa político con el que se presentaba.

El jefe de Gobierno se ha convertido en un órgano constitucional cuya tarea principal consiste en la dirección y coordinación del Gobierno. Para ello, se ha dotado a la jefatura de Gobierno de una serie de funciones y competencias en exclusiva, aunque en ocasiones necesiten la participación de otras instituciones. Así, el jefe de Gobierno propone discrecionalmente la disolución de la Cámara baja por Decreto adoptado en un Consejo de ministros (art. $104 \mathrm{CM}$ ); igualmente, éste puede plantear la cuestión de confianza (art.103,1 CM). También puede presentar las leyes, antes de su promulgación, al Tribunal Constitucional (art.132,3 CM) y proponer un referéndum (172,1 CM), aunque formalmente la propuesta debe pasar primero por el Consejo de ministros para garantizar -en teoría- la participación -formal- del jefe del Estado (art. 173,2 CM).

Según la nueva Constitución el poder reglamentario depende directamente de la potestad ejecutiva representada por el jefe de Gobierno y su Gobierno (art. $90 \mathrm{CM}$ ). Todo asunto no incluido en el ámbito de la ley entra en el dominio reglamentario (art. $72 \mathrm{CM}$ ). Esto explica que el proceso constituyente no haya supuesto ningún cambio en cuanto a la potestad reglamentaria del jefe de Gobierno pre-constitucional, ya desde 1962 con la única excepción de la Constitución de 1970 adoptada después de una declaración de estado de excepción y que concentró todo el poder en la Corona (art. 29 CM de 1970). En este trabajo hemos defendido que la actual Constitución requiere una participación de todos los ministros en la propuesta del reglamento. También creemos que existe una obligación constitucional de refrendar los actos reglamentarios por parte de los ministros encargados de su ejecución (art. 90 CM).

En la práctica del primer Gobierno post-constitucional hay que destacar que diversos factores internos y externos, jurídicos y políticos, junto al peso histórico de la monarquía han condicionado el margen de maniobra del jefe de Gobierno. Podemos clasificar estos factores en tres grupos:

1- Factores psicológicos: en referencia a la capacidad de dirección y a la personalidad o carisma del jefe de Gobierno.

2- Factores jurídicos y constitucionales: el conjunto de nuevas reglas y procedimientos previstos en la Constitución de 2011. Estos requieren para su plena eficacia una interpretación democrática ante la ambigüedad de los textos que organizan la relación cooperativa entre el jefe de Gobierno y el Monarca. Este es el caso del art. 48 CM (la presidencia del Consejo de Ministros con previa delegación del jefe del Estado) o del art.49 CM (el nombramiento de los altos cargos).

3- Factores políticos: la existencia o no de una mayoría parlamentaria sólida, ya sea dentro del partido mayoritario o en la coalición de partidos que apoyan al Gobierno ${ }^{36}$. No puede descartarse tampoco la presión de las fuerzas políticas y sociales con gran influencia en Marruecos, sobre todo, las fuerzas del Estado profundo conocido por "Majzén".

\footnotetext{
${ }^{36}$ El compromiso de buen Gobierno pactado en el Acta de la mayoría gubernamental, no ha conseguido evitar la crisis sucesiva en la unidad de los partidos de la coalición, cuando han arreciado las críticas del nuevo secretario general del segundo partido (Ballahmidi 2013).
} 
Pues bien, del análisis combinado de estos factores parece detectarse un desequilibrio institucional favorable a la Corona, en ocasiones propiciado por la ambigüedad del mismo texto constitucional, en otros casos debido a las interpretaciones del mismo. Este desequilibrio, en nuestra opinión, tiene un efecto negativo destacado, como es que impide profundizar en la cooperación entre los poderes del Estado. Uno de los mejores ejemplos de este desequilibrio consiste en la relación del Monarca con la institución del jefe de Gobierno. Esta relación es en algunos puntos poco clara, y en muchas ocasiones nos hace dudar de quien es el verdadero jefe del poder ejecutivo, y nos hace preguntarnos si estamos ante una forma de un poder ejecutivo Dual o ante una Monarquía Constitucional, y no así Parlamentaria. Son especialmente criticables las convocatorias del Consejo de Ministros a iniciativa del jefe del Estado y bajo su presidencia. Asimismo, la participación exorbitante del Rey en el nombramiento en las funciones administrativas, sin tener por ello naturaleza religiosa ni judicial ni diplomática ni militar, recuerda los métodos antiguos del pasado. Este desequilibrio deberá afrontarse en la práctica y en los textos de desarrollo legislativo de los preceptos constitucionales de forma más amplia, en los cuales el debate actual entre las doctrinas conservadoras y modernas inevitablemente volverá a aflorar.

El futuro del desarrollo político parece complejo, sobre todo ante el fracaso del nuevo texto constitucional a la hora de resolver el primer bloqueo institucional en la formación del Gobierno tras las elecciones generales del 7 de octubre de 2016, y sustituir a Benkirane, secretario general del PJD, por Al-Othmani número dos dentro de la misma formación para formar un Gobierno con muy poca relación dinámica con los resultados de las segundas elecciones legislativas después de la primavera democrática.

\section{Bibliografía}

ANOUZLA, Ali (marzo de 2013): “Nominations d'ambassadeurs, qu'est ce qui a changé?", en Lakome, 12/3/2013, disponible en http://www.maghress.com/fr/lakomefr/1502 . [Consulta: 24 de febrero de 2017].

BALLAHMIDI, Ahmed (junio de 2013): "las declaraciones de Chabat irritan a los líderes de la coalición del Gobierno", en árabe, artículo publicado en Ahdath Maghribía, disponible en http://www.ahdath.info/?p=105493 . [Consulta: 15 de junio de 2013].

BENDOUROU, Omar (2012): "La consécration de la monarchie gouvernante", en L'Année du Maghreb, VIII, 2012.

BENKIRANE, Abdelilah (diciembre de 2011): entrevista publicada en Periódico Attajdid, número 8780, 2-11/12/2011.

BENKIRANE, Abdelilah (diciembre de 2011): entrevista publicada en Periódico Almassaa, número 1612, 30/12/2011.

BENKIRANE, Abdelilah (marzo de 2013): Texto de la entrevista concedida al periódico Libanes "Al khabar", publicado el lunes 04/03/2013, disponible también en http://hespress.com/politique/73838.html . [Consulta: 05 de febrero de 2017].

BENNANI, Driss y BOUDARHAM, Mohammed (diciembre de 2012): "PJD-Monarchie. Fin de la récreation", en Tel Quel, 13/12/2012.

DESRUES, Thierry (2007): "L'emprise de la monarchie marocaine entre fin du droit d'inventaire et déploiement de la technocratie palatiale", en L'Année du Maghreb, III, 2007, CNRS, Paris. pp. 231273, disponible en https://anneemaghreb.revues.org/372 . [Consulta: 24 de febrero de 2017].

DESRUES, Thierry (2013): "Primer año de gobierno islamista en Marruecos. El poder de siempre en una coalición inédita”, en Anuario del Mediterráneo 2013. IEMED, Barcelona. 
EL MOUSSADEQ, Rkia (2012), El Derecho Constitucional y las Instituciones Políticas, el sistema político marroquí y otros sistemas contemporáneos, en árabe, segunda parte, editorial Dar Toubkal, Casablanca.

ELAHMADI, Moshine (2010): “Modernisation du champ religieux au Maroc 1999-2009”, en AA. VV., Une décennie de réformes au Maroc (1999-2009), Karthala, Paris.

GONZÁLEZ-TREVIJANO SÁNCHEZ, Pedro (1998), El refrendo, Centro de Estudios Políticos y Constitucionales, Madrid.

GONZÁLEZ-TREVIJANO SÁNCHEZ, Pedro (2000), El Tribunal Constitucional, Aranzadi, Navarra.

HAMI DINE, Abdelali (25-26 de junio de 2011): "Desde el dominio de la institución real hacía una necesaria convivencia con el jefe de Gobierno", en árabe, Akhbar Alyawm, núm. 480.

HERNANDO de LARRAMENDI, Miguel (2013): "El islamismo político y el ejercicio del poder tras el despertar árabe: los casos de Egipto, Túnez y Marruecos", en El islamismo en (R) evolución: movilización social y cambio político, Cuaderno de Estrategia, no 163 (Ejemplar dedicado a: Islamismos en ( $r$ ) evolución: movilización social y cambio político), pp. 71-116, disponible en https://dialnet.unirioja.es/servlet/articulo?codigo=4473746 . [Consulta: el 24 de febrero de 2017]. MATEOS DE CABO, Óscar Ignacio (2006), El presidente del Gobierno en España, Status y funciones, La Ley, Universidad Rey Juan Carlos, Madrid.

MADANI, Mohammed (2011): “La nueva Constitución, la centralización del poder y la debilidad de las garantías", en AA. VV., artículo en árabe, La nueva Constitución y la fantasía del cambio, publicado en la serie "Dafatir wijhat nadar" núm. 24, ed. Matbaat Annajah Aljadida, Casablanca, primera edición, pp. 85-106.

MAUS, Didier (2012): "L'Exécutif dans la Constitution marocaine de 2011", AA. VV., en La Constitution Marocaine de 2011, Analyses et commentaires, Paris, LGDJ, pp. 71-84.

MELLONI, David (2012): "Le nouvel ordre constitutionnel marocain: de la monarchie gouvernante à la monarchie parlementaire", en AA. VV., La Constitution marocaine de 2011. Analyses et commentaires, Paris, LGDJ, pp. 7-46.

MOHAMED VI, Rey de Marruecos: Los textos completos de los discursos de 9 de marzo y de 17 de junio de 2011, disponibles en http://www.maroc.ma/es/discursos-reales, [Consulta: 20 de enero de 2017].

MOLAS, I. y PITARCH, I. (1987), Las Cortes Generales en el sistema parlamentario de Gobierno, Tecnos, Madrid.

MONJIB, Maâti (2013): "Constitutionally Imbalanced", en Sada Journal, August 8.

MOUADEN, Abdelhay (2012): en una entrevista publicada en el periódico Akhbar Al-yawme, número 640, 3/01/2012.

MOUMINE, Mourad (2002), La responsabilidad del Gobierno entre la influencia política y la influencia partidista, en árabe, trabajo de investigación para obtener D.E.S.A. en Derecho Público, (2001-2002), Facultad de Ciencias Jurídicas, Económicas y Sociales, Oujda.

PAREJO FERNÁNDEZ, Ma Angustias (2004): "Principio y fin de siglo en clave política: alternancia, sucesión e islamismo político en Marruecos", en Carmelo Pérez, ed., El mundo árabe e islámico ante los retos del futuro, Editorial Universidad de Granada, Granada, pp. 102-103.

PAREJO FERNÁNDEZ, Ma Angustias y FELIU Laura (2013): “Marruecos: la reinvención de un sistema autoritario" en Ferrán Izquierdo Brichs (ed.), Poder y regímenes en el Mundo Árabe Contemporáneo, Fundación CIDOB, pp. 105-144, disponible en file:///C:/Users/abdes/Downloads/26_PODER+Y+REG\%C3\%8DMENES+EN+EL+MUNDO+\%C3\%81R ABE.pdf . [Consulta: 24 de febrero de 2017].

REDOUANI, Mohammed (2004), El desarrollo político en Marruecos: La formación de la autoridad ejecutiva y su ejercicio, en árabe, tesis doctoral en derecho público, facultad de derechos, Agdal, Radat.

RUIZ MIGUEL, Carlos (2012): La Constitución marroquí de 2011. Análisis crítico, Madrid, Dykinson. 
RUIZ RUIZ, J.J. (2014): “La Constitución marroquí de 2011 y el ensayo de parlamentarización de la monarquía”, Revista de Estudios Políticos, Núm. 164, abril-junio, pp. 33-85.

SAAF, Abdallah (2011): "Une "sortie" du despotisme: I'expérience marocaine de "transition" politique. Démocratie, sécurité, et développement", disponible en file://C:/Users/abdes/Downloads/experience marocaine de transition politique.pdf. [Consulta: 24 de febrero de 2017].

SAÏDY, Brahim (2012), "La structure constitutionnelle des relations civilo-militaires au Maroc", AA. VV, en La Constitution Marocaine de 2011, Analyses et commentaires, Paris, LGDJ, pp. 139-170.

SAÏDY, Brahim (enero 2011), "Defence and Security in Arab World in 2011", en Al Jazeera Centre For Studies, Qatar.

SAÏDY, Brahim (2007): "Les relations civilo-militaires au Maroc: le facteur international revisité", en Politique étrangèr, Euerope, identités et politiques, IFRI ed., (pp. $589-603$ ), artículo disponible en http://www.cairn.info/revue-politique-etrangere-2007-3-page-589.htm. [Consulta: 20 de enero de 2017].

WALD ALKABLA, Idriss, (2009): “Los generales inválidos y los soldados que quiere el Rey", en árabe, disponible en http://karimroyal.canalblog.com/archives/2009/02/13/12597249.html . [Consulta: 14 de enero de 2016]. 